PROF. SHIDA YOUSEFI (Orcid ID : 0000-0002-9855-4305)

DR. DAGMAR SIMON (Orcid ID : 0000-0001-8965-9407)

Received Date : 16-Jan-2017

Accepted Date : 22-Jan-2017

Article type $\quad$ : Original Article: Skin and Eye Diseases

\title{
Evidence for a role of eosinophils in blister formation in bullous pemphigoid
}

Elisabeth de Graauw ${ }^{1}$, Cassian Sitaru², Michael Horn ${ }^{3}$, Luca Borradori ${ }^{4}$,

Shida Yousefi ${ }^{1}$, Hans-Uwe Simon ${ }^{1^{*}}$ and Dagmar Simon ${ }^{4^{*}}$

${ }^{1}$ Institute of Pharmacology, University of Bern, Bern, Switzerland; ${ }^{2}$ Department of Dermatology and Centre for Biological Signaling Studies (BIOSS), University Medical Center Freiburg, Freiburg, Germany; ${ }^{3}$ Centre of Laboratory Medicine, Inselspital, Bern University Hospital, Bern, Switzerland; ${ }^{4}$ Department of Dermatology, Inselspital, Bern University Hospital, University of Bern, Bern, Switzerland.

${ }^{*}$ Corresponding authors:

Dagmar Simon, MD

Department of Dermatology, Inselspital, Bern University Hospital

CH-3010 Bern, Switzerland

Tel.: +41 31632 2278; Fax: +41 31632 2233; E-mail: dagmar.simon@insel.ch

This article has been accepted for publication and undergone full peer review but has not been through the copyediting, typesetting, pagination and proofreading process, which may lead to differences between this version and the Version of Record. Please cite this article as doi: 10.1111/all.13131

This article is protected by copyright. All rights reserved. 
Hans-Uwe Simon, MD, PhD

Institute of Pharmacology, University of Bern

CH-3010 Bern, Switzerland

Tel.: +41 31632 3281; Fax: +41 31632 4992; E-mail: hus@pki.unibe.ch

Conflict of interest: The authors declare that they have no conflict of interest.

Key words: bullous pemphigoid, BP autoantibody, blister formation, eosinophils, interleukin-

5 , degranulation, adhesion

Abbreviations:

BFA, Brefeldin A; BP, Bullous pemphigoid; BPS, Bullous pemphigoid serum; DEJ, Dermalepidermal junction; DES, Dermal-epidermal separation; DHR, Dihydro-rhodamine; DNase, Deoxyribonuclease; DPI, Diphenyleneiodonium; EET, Eosinophil extracellular trap; ECP, Eosinophil cationic protein; EDN, Eosinophil-derived neurotoxin ; FcR, Fc receptor; IL, Interleukin; MBP, Major basic protein; NHS, Normal human serum; PMA, Phorbol-myristateacetate; ROS, Reactive oxygen species

\section{Abstract}

Background: Bullous pemphigoid (BP) is an autoimmune bullous disease of the skin characterized by subepidermal blister formation due to tissue-bound and circulating autoantibodies to the hemidesmosomal antigens BP180 and BP230. Although eosinophils and their toxic mediators are found abundantly in BP lesions, their role in blister formation has remained unclear.

This article is protected by copyright. All rights reserved. 
Objective: To investigate the role of eosinophils in the pathogenesis of BP with a specific focus on blister formation and to define conditions inducing dermal-epidermal separation (DES).

Methods: In an ex vivo human model of $\mathrm{BP}$, normal human skin cryosections were incubated with purified human peripheral blood eosinophils with or without activation in the presence or absence of BP autoantibodies, brefeldin A, diphenyleneiodonium (DPI), DNase, or blocking $\mathrm{F}\left(\mathrm{ab}^{\prime}\right)_{2}$ fragments to CD16, CD18, CD32 and CD64. DES was assessed by light microscopy studies and quantified using Fiji software.

Results: Following activation with IL-5 and in the presence of BP autoantibodies, eosinophils induced separation along the dermal-epidermal junction of ex vivo skin. DES was significantly reduced by blocking any of the following: $F c \gamma$ receptor binding $(p=0.048)$, eosinophil adhesion $(p=0.046)$, reactive oxygen species (ROS) production $(p=0.002)$, degranulation $(p<0.0001)$, or eosinophil extracellular trap (EET) formation $(p=0.048)$.

Conclusions: Our results provide evidence that IL-5-activated eosinophils directly contribute to $\mathrm{BP}$ blister formation in the presence of $\mathrm{BP}$ autoantibodies. DES by IL-5-activated eosinophils depends on adhesion and $\mathrm{Fc} \gamma$ receptor activation, requires elevated ROS production and degranulation, and involves EET formation. Thus, targeting eosinophils may be a promising therapeutic approach for BP.

\section{Introduction}

Eosinophils are found in a broad spectrum of infectious and non-infectious skin diseases, despite the fact that the skin is devoid of eosinophils under physiologic conditions (1). Eosinophils are under the control of eosinophil hematopoietins; in particular interleukin (IL)-5 plays a critical role in regulating the production, differentiation, activation, trafficking and survival of eosinophils (2). The primary function of eosinophils has been considered to be related to host defence as they can function as potent destructive effector cells (3). By degranulation of toxic granule proteins or eosinophil extracellular trap (EET) formation, eosinophils are able to kill parasites and bacteria (3-5). On the other hand, eosinophils have also been accused of causing tissue damage $(3,7)$. According to their cytokine expression, functionally different subpopulations of eosinophils have been identified in skin diseases that might potentially regulate inflammatory responses and/or fibrosis (6).

This article is protected by copyright. All rights reserved. 
Bullous pemphigoid (BP) is the most common autoimmune blistering disease of the skin which is associated with an autoimmune response to BP180 and BP230, two structural components of junctional adhesion complexes, the hemidesmosomes, and subsequent damage to the dermal-epidermal junction (DEJ) $(8,9)$. Autoreactive $B$ and $T$ cell responses against the hemidesmosomal antigens BP180 and BP230 have also been identified $(10,11)$. BP antigen-specific T cells were shown to produce both Th1 (interferon (IFN)- $\mathrm{Y}$ ) and Th2 (IL5 and IL-13) cytokines (10).

Moreover, eosinophil infiltration and dermal-epidermal separation (DES) are typical histological findings in BP. In agreement with the dominant presence of eosinophils, IL-5 as well as eotaxins were found abundantly in blister fluids $(12,13)$. On the other hand, despite the observations of metalloproteinase (MMP)-9 expression by eosinophils at sites of blister formation capable of cleaving the extracellular, collagenous domain of BP180 in vitro (14), deposition of granule proteins such as major basic protein (MBP), eosinophil-derived neurotoxin (EDN) and eosinophil cationic protein (ECP) in BP lesions (15, 16), as well as eosinophil extracellular DNA traps (EETs) directed toward the DEJ in BP specimens (17), a direct contribution of eosinophils to blister formation in BP has not yet been shown. In this study, applying an ex vivo skin model, we aimed at investigating the role of eosinophils in the pathogenesis of BP with a specific focus on blister formation.

\section{Methods}

\section{Patient materials}

BP serum (BPS) samples $(n=30)$ were obtained from untreated patients with clinically, histopathologically and serologically confirmed BP according to current criteria (18). Pooled BPS $(n=30)$ containing both BP180 and BP230 as assessed by ELISA with a mean titre of 106.13 U/ml and $39.88 \mathrm{U} / \mathrm{ml}$, respectively, were used $(19,20)$. Normal human serum (NHS) samples were obtained from healthy donors without any history of immunosuppression and/or autoimmunity. Eosinophils were collected from the peripheral blood of patients with eosinophilic skin diseases attending the Department of Dermatology as well as from patients with hypereosinophilia diagnosed by the Institute of Pharmacology of the University of Bern $(21,22)$. Healthy human foreskin was obtained from routine circumcisions. The study has been approved by the Cantonal Ethics Committee (KEK) Bern. Written informed consent was obtained from all patients or their caregivers, prior to blood and tissue sampling.

This article is protected by copyright. All rights reserved. 


\section{Induction and evaluation of DES}

DES was analysed using an ex vivo model of DES as previously described (19) with minor modifications. Briefly, human foreskin was washed and embedded in an optimum cuttingtemperature compound (Tissue-Tek® O.C.T. TM compound, Sakura Finetek Europe B.V, Alphen aan den Rijn, The Netherlands) and stored at $-20^{\circ} \mathrm{C}$. Six $6-\mu \mathrm{m}$ thick cryosections were placed on adhesive microscope slides (Starfrost $\AA$ ), Medite Service AG, Dietikon, Switzerland). BPS and NHS were diluted 1:2 with PBS and applied to the skin sections for 2 $\mathrm{h}$ at $37^{\circ} \mathrm{C}$, followed by washing the slides with PBS. Eosinophils were resuspended in DMEM (DMEM plus GlutaMAX ${ }^{\mathrm{TM}}$, Gibco®, Life Technologies Europe B.V., Zug, Switzerland), including $10 \%$ foetal calf serum to avoid their immediate adherence to the slides, and subsequently added to the sections in the prepared chambers for an incubation of $4 \mathrm{~h}$ at $37^{\circ} \mathrm{C}$. Tissue sections were then fixed with $3.7 \%$ formalin and stained with hematoxylin and eosin (H\&E). DES was evaluated by light microscopy studies. The total lengths of DES and DEJ, respectively, were calculated using Fiji (23). DES was given as a percentage of separation at the DEJ. To assess tissue damage semi-quantitatively in indicated experiments, we scored the extent of skin damage and presence of DES. Each experiment was repeated at least three times to confirm reproducibility.

\section{Isolation of human eosinophils}

Peripheral blood eosinophils were isolated by density-gradient centrifugation using the FicollHypaque technique (Pancoll, Bioswisstec AG, Schaffhausen, Switzerland). The upper phase containing peripheral blood mononuclear cells (PBMCs) was removed. The lower phase containing, eosinophils, neutrophils and erythrocytes was treated with a lysis solution (1.6 $\mathrm{mol} / \mathrm{l} \mathrm{NH}_{4} \mathrm{Cl}, 100 \mathrm{mmol} / \mathrm{l} \mathrm{KHCO}_{3}, 1 \mathrm{mmol} / \mathrm{l}$ EDTA) to remove erythrocytes. Isolation of eosinophils was followed by a negative selection procedure with monoclonal antibodies bound in bispecific, Tetrameric Antibody Complexes (TAC), which were directed against CD2, CD3, CD14, CD16, CD19, CD20, CD36, CD56, CD123, glycophorin A and dextran (EasySep $^{\mathrm{TM}}$, STEMCELL Technologies, Grenoble, France). The negatively collected eosinophils were analysed by Hemacolor ${ }^{\circledR}$ Rapid staining (Merck Millipore, Darmstadt, Germany) and light microscopy. Fractions containing $\geq 95 \%$ mature eosinophils were employed for further experiments.

This article is protected by copyright. All rights reserved. 


\section{Activation of eosinophils}

In indicated experiments, eosinophils were stimulated with $25 \mathrm{ng} / \mathrm{ml} \mathrm{IL-5} \mathrm{(R \& D} \mathrm{Systems,}$ Minneapolis, USA) or $100 \mathrm{ng} / \mathrm{ml} \mathrm{IFN-}$ (R\&D Systems) for $20 \mathrm{~min}$ at $37^{\circ} \mathrm{C}$ and/or with $10 \mathrm{nM}$ complement factor 5a (C5a, Hycult Biotech, Uden, The Netherlands), $100 \mathrm{ng} / \mathrm{ml}$ lipopolysaccharides (LPS, Sigma-Aldrich, Buchs, Switzerland), $10 \mathrm{nM} \mathrm{N-formyl-L-methionyl-}$ L-leucyl-L-phenylalanine (fMLF, Sigma-Aldrich) or $25 \mathrm{nM}$ phorbol-myristate-acetat (PMA, Calbiochem, Merck\&Cie, Darmstadt, Germany) for $15 \mathrm{~min}$ at $37^{\circ} \mathrm{C}$ before adding them to the cryosections.

\section{Blocking adhesion and Fc $\gamma$ receptors (FcpR)}

To block adhesion, eosinophils were incubated with $20 \mu \mathrm{g} / \mathrm{ml}$ mouse $F(a b ')_{2}$ fragments directed against human CD18 (Ancell Corporation, Bayport, USA) on ice for $45 \mathrm{~min}$. To block FcyR-mediated effects, eosinophils were incubated with $10 \mu \mathrm{g} / \mathrm{ml}$ mouse $F(a b)_{2}$ fragments against CD16, CD32 and CD64 (all from Ancell Corporation, Bayport, USA) on ice for 45 min. Isotype-matched mouse anti-human $F\left(a b^{\prime}\right)_{2}$ fragments (Jackson ImmunoResearch Europe Ltd. Suffolk, UK) served as controls.

\section{Pharmacological inhibition of ROS production, degranulation and EET formation}

To block reactive oxygen species (ROS) production, eosinophils were incubated with the NAPDH oxidase inhibitor diphenyleneiodonium chloride (DPI, Calbiochem, Merck Millipore, Darmstadt, Germany) at increasing concentrations of $1-75 \mu \mathrm{M}$ for $30 \mathrm{~min}$ at $37^{\circ} \mathrm{C}$. To block degranulation, eosinophils were incubated with $10 \mu \mathrm{g} / \mathrm{ml}$ brefeldin A (BFA, Sigma-Aldrich co, Buchs, Switzerland) which inhibits vesicular transport and granule emptying (24) for 30 min at $37^{\circ} \mathrm{C}$. To degrade the DNA scaffold of EETs (5), $100 \mathrm{U} / \mathrm{ml}$ of deoxyribonuclease I (DNase I, Worthington Biochemical Corporation, Lakewood, USA) was used. All reagents were added to eosinophils prior to their application on skin sections.

To quantify ROS production, $1 \mu \mathrm{M}$ dihydro-rhodamine-123 (DHR, Sigma-Aldrich, Buchs, Switzerland) was added to activated eosinophils prior to their addition to human skin sections incubated with BPS, NHS or PBS in a black, glass-bottom 96-well plate (Greiner Bio-One $\mathrm{GmbH}$, Frickenhausen, Germany) (25). Fluorescence activity of the DHR 123 was measured at excitation $485 \mathrm{~nm}$ and the fluorescence emission at $538 \mathrm{~nm}$, using a SpectraMaxM2 plate reader (Bucher Biotech, Basel, Switzerland) over a time period of $2 \mathrm{~h}$.

This article is protected by copyright. All rights reserved. 


\section{Statistical analysis}

Data were analysed using Graph Pad Prism 5 software (La Jolla, CA, USA) and presented as means \pm SEM. For comparison between treatments, unpaired 2-tailed $t$-tests or one-way ANOVA followed by Tukey's multiple comparisons tests were applied. $P$ values of $<0.05$ were considered significant.

\section{Results}

\section{IL-5 - activated eosinophils induce diffuse skin damage with focal DES}

In order to investigate the ability of eosinophils to induce DES, isolated peripheral blood eosinophils at concentrations of $10-40 \times 10^{6} \mathrm{cells} / \mathrm{ml}$ were added to human skin cryosections in the presence of either BPS or NHS. Under these circumstances, eosinophils failed to induce DES (Fig. 1A, 1B). In contrast, when the whole leukocyte fraction $\left(30 \times 10^{6} \mathrm{cells} / \mathrm{ml}\right)$ or isolated neutrophils $\left(30 \times 10^{6}\right.$ cells $\left./ \mathrm{ml}\right)$ were used, we observed an extensive DES of $85.2 \% \pm 3.4$ and $47.2 \% \pm 7.8$, respectively, in the presence of BPS (Fig. 1A, 1C, 1D), but not NHS.

To evaluate whether eosinophils stimulated with pro-inflammatory cytokines and mediators are able to induce DES in the ex vivo skin model, eosinophils were activated with IL-5 either alone or together with C5a or LPS before adding them to the cryosections. After a 4-h incubation, IL-5-activated eosinophils caused a diffuse tissue damage with focal separation at the DEJ that was not further enhanced upon additional activation with C5a or LPS (Fig. 1E, 1F). As a positive control, we activated eosinophils with PMA, which is known to be a strong, but nonspecific stimulator of eosinophils $(5,26)$. PMA-stimulated eosinophils at concentrations of $20-30 \times 10^{6} / \mathrm{ml}$ induced massive diffuse skin damage leading to a complete loss of tissue structure (Fig. 1E). Moreover, we observed extensive extracellular eosinophil granule depositions in areas of tissue damage (Fig. 1G). Addition of PMA in the absence of eosinophils had no effect (Fig. 1H). Taken together, these results indicate that eosinophils activated with either IL-5 or PMA induced diffuse skin damage in an autoantibody-independent manner.

This article is protected by copyright. All rights reserved. 


\section{Synergistic effect of interleukin-5 and BP autoantibodies on DES}

We next assessed whether BP autoantibodies have an impact on the DES-inducing effect of IL-5-activated eosinophils in our ex vivo skin model. Interestingly, in the presence of BP autoantibodies, we observed a line-up of IL-5-activated eosinophils at the DEJ after $3 \mathrm{~h}$ of incubation, where after $4 \mathrm{~h}$, a marked DES was evident affecting $21.2 \% \pm 2.3$ of the DEJ (Fig. 2A-C). In contrast, IL-5-activated eosinophils in the presence or absence of NHS, induced significantly less DES of $9.3 \% \pm 2.8$ and $9.8 \% \pm 1.8$, respectively, suggesting that BP autoantibodies enhanced the activating effect of IL-5 on eosinophils to induce DES (Fig. $2 A, 2 D)$. Additional stimulation of IL-5 and BPS - activated eosinophils with either IFN- $\gamma$, LPS or fMLF did not further increase the DES (data not shown).

\section{Eosinophil-induced DES requires FcyR and CD18}

A critical role for $\mathrm{F} c \gamma \mathrm{R}$ in BP pathogenesis has been demonstrated in an animal model (26). In order to investigate the importance of FcyRs expressed by eosinophils for the binding of IgG autoantibodies present in BP serum, we used blocking $F\left(a b^{\prime}\right)_{2}$ fragments directed against CD16 (FcyRIII), CD32 (FcyRII) and CD64 (FcyRI) to block autoantibody binding on eosinophils. As a control, we used control $F(a b)_{2}$ fragments in these experiments. The blockage of FcyRs significantly reduced DES (Fig. 3A-C), suggesting that BP autoantibodies directly activate eosinophils and/or facilitate attraction of eosinophils to the DEJ in the presence of IL-5 through FcyRs.

Since adhesion has been shown to play a crucial role for eosinophil activation (27), we tested whether blocking $F(a b ')_{2}$ fragments directed against $C D 18$, the common $\beta$ chain shared by leukocyte integrins, inhibited eosinophil-mediated DES. Blockage of CD18 significantly reduced DES, whereas isotype-matched control $F\left(a b^{\prime}\right)_{2}$ fragments did not (Fig. $3 \mathrm{D}-\mathrm{F})$. Taken together, binding and adhesion of IL-5-activated eosinophils in the presence of BP autoantibodies appear to be mediated by FcyRs and CD18.

\section{ROS production, degranulation and EET formation are involved in DES induction by activated eosinophils}

We were next interested in potential molecular mechanisms by which IL-5 and BPSactivated eosinophils induce DES. ROS production has been shown to be required for neutrophil-dependent autoantibody-induced tissue damage in an experimental model of 
epidermolysis bullosa acquisita (28). Therefore, to evaluate the role of ROS in eosinophilinduced DES, we tested the effect of DPI, a NADPH oxidase inhibitor, in our ex vivo skin model. Incubation of IL-5 and BPS - activated eosinophils with DPI decreased DES in a concentration-dependent manner (DES at $1 \mu \mathrm{M}, 15.2 \% \pm 3.9 ; 50 \mu \mathrm{M}, 8.0 \% \pm 4.0 ; 75 \mu \mathrm{M}$, $2.8 \% \pm 1.4$; Fig. $4 \mathrm{~A}, 4 \mathrm{D}, 4 \mathrm{E})$. When the production of ROS by eosinophils co-incubated with skin sections was measured, we observed a rapid increase in ROS production in IL-5 activated eosinophils after $5 \mathrm{~min}$. ROS levels were then relatively constant for about $60 \mathrm{~min}$ and subsequently declined. In contrast, PMA-stimulated ROS production continued even after $60 \mathrm{~min}$. DPI completely blocked IL-5-induced ROS production. It should be noted that we observed no increase in ROS production of IL-5-activated eosinophils in the presence BPS (Fig. 4H).

Since eosinophil granule deposits have been observed in BP lesions $(15,16)$, we aimed to study the role of eosinophil degranulation on DES induction. Blocking degranulation of activated eosinophils by BFA $(24,29,30)$ resulted in a significant inhibition of DES (Fig. $4 \mathrm{~B}, 4 \mathrm{~F}$ ) suggesting a direct contribution of eosinophil granule proteins to blister formation.

In BP lesions, the presence of EETs consisting of DNA scaffold which granule proteins has been observed in close proximity to the DEJ (17). Furthermore, a destruction of the DNA scaffold by DNase was shown to abolish their functional properties in vitro $(4,5)$. To evaluate a possible role of EETs in DES, DNase was added to IL-5 and BPS - activated eosinophils prior to their application on the skin sections. DNase treatment significantly reduced DES induced by activated eosinophils (Fig. 4C, 4G).

\section{Discussion}

A direct contribution of eosinophils to blister formation in BP has long been suggested because of their characteristic presence in lesional skin, the demonstration of extracellular granule deposits near blisters $(15,16)$, EETs directed toward the DEJ (17), and BP antigen cleavage by the MMP-9 released by eosinophils (14). So far, animal models have demonstrated a possible pathogenic role of neutrophils, mast cells, and macrophages in BP (31-33). However, although eosinophils are the dominant cell type recruited to BP lesions, their contribution to blister formation has remained unclear.

In this study, we provide evidence that activated eosinophils directly contribute to blister formation in BP patients. In order to induce DES, eosinophils required IL-5 activation. In the presence of BP autoantibodies, DES mediated by IL-5-activated eosinophils was 
significantly increased. Under these conditions, we also observed an eosinophil lining at the DEJ, but no increased ROS production. Therefore, it is possible that eosinophils bind through their FcyRs to the autoantibodies bound to the DEJ that, however, seem to have less importance for eosinophil activation. DES might then be mediated by eosinophil granule proteins which damage the skin either alone or in the context of EET formation $(4,9)$.

In agreement with a recent study, we observed that eosinophils activated solely with BP antibodies were not able to induce DES (34). Noteworthy, also similar to our study, IL-5activated eosinophils have previously been demonstrated to bind throughout the dermis and not specifically to the basement membrane (35). Our observations suggest that activated eosinophils may cause diffuse tissue damage with minimal DES, while in the presence of BPS, a line-up of eosinophils occurs at the DEJ, leading to an increased dermal-epidermal splitting.

BP antibodies that are present in both serum and tissue of patients with BP (36) have been demonstrated to be essential for subepidermal blister formation in experimental mouse models (37). Antibodies against the $180-\mathrm{kD}$ BP antigen were bound to the extracellular domain along the plasma membrane, while those against the 230-kD BP antigen were directed to the intracellular domain of the hemidesmosome (38). These antibodies were mainly of the IgG type and recognized the non-collagenous (NC) site of BP180 $(39,40)$. As BPS and purified IgG from the same sera were shown to have identical effects on DES in the ex vivo model and BPS-depleted of $\lg G$ reactive to $\mathrm{NC16A}$, or $\left.\mathrm{F}(\mathrm{ab})_{2}\right)_{2}$ fragments directed to NC16A, failed to induce DES (19), we abstained from a purification and detailed characterization of the BPS in the present study.

The function of an anti-mBP180 lgG depends entirely on its Fc domain, whereas $F(a b)_{2}$ of $\lg G$ failed to induce BP mediated by neutrophils in an animal model (26). Human eosinophils have been shown to constitutively express FcyRII (CD32) and small amounts of FcyRIII (CD16) that were enhanced upon IFN- $\gamma$ stimulation $(41,42)$. Our results show that DES in the presence of BPS was highly dependent on functional Fc $\gamma$ Rs on eosinophils. A role of other Fc receptors in eosinophil-mediated blister formation, e.g. Fc $\varepsilon$ receptor in the subgroup of BP patients exhibiting IgE autoantibodies to BP180 or BP230 $(43,44)$ and responding to anti-IgE therapy (45), seemed unlikely since $\lg E$ autoantibodies in BP were shown to activate basophils and mast cells (46) rather than eosinophils that lack functionally active high-affinitiy $\lg E$ receptors $(\mathrm{Fc \varepsilon RI})(47,48)$.

This article is protected by copyright. All rights reserved. 
In lesional BP skin, keratinocytes have been demonstrated to express the intercellular adhesion molecule (ICAM)-1 (49) and thus might attract and bind to eosinophils bearing CD11 and CD18 on their surface (50). In our ex vivo skin model, blocking CD18 with an anti-CD18 $\mathrm{F}(\mathrm{ab})_{2}$ fragment inhibited DES mediated by IL-5 and BPS-activated eosinophils, indicating that eosinophil adhesion may also play a role for blister formation in BP.

Eosinophil degranulation with the release of toxic granule proteins subsequently leading to keratinocyte damage and DES has long been suggested as a key pathogenic event in BP $(51,52)$. Moreover, the deposition of granule proteins was shown to precede blister formation (15). Blocking eosinophil degranulation resulted in a significant decrease in DES formation, suggesting that eosinophil granule proteins play an important role for subepidermal blister formation in BP. Eosinophil granule proteins may also occur in association with extracellular DNA, forming so-called EETs (4, 5). Earlier work suggested that such EETs seem to target the DEJ in BP lesions (17). The observation that the destruction of the DNA scaffold by DNase significantly reduced DES induced by activated eosinophils point to the possibility that granule proteins present in EETs contribute to the subepidermal splitting in our ex vivo BP model.

NADPH oxidase was shown to be required for autoantibody-dependent tissue damage by neutrophils enabling them to release superoxide in the extracellular space (28, 53). Compared with neutrophils, eosinophils may form even larger amounts of the NADPH oxidase complex upon activation (54). Moreover, increased ROS production has been demonstrated to be crucial for EET formation $(4,5)$. In this study, we show that pharmacological blocking of ROS production significantly reduced DES induction by activated eosinophils in a concentration-dependent manner. In this experimental setting, however, we were unable to distinguish whether the DPI effect was owing to an inhibition of EET formation, degranulation or extracellular ROS release, or a combination of these possibilities.

Taken together, our study demonstrated that in the presence of BPS, IL-5-activated eosinophils had the capacity to split skin at the DEJ, thus directly contributing to subepidermal blister formation in BP. DES induced by activated eosinophils required eosinophil adhesion and functional FcyRs, as well as ROS production and release of granule proteins which appear to mediate tissue damage either alone or in association with EETs. For future study of the role of eosinophils in BP in vivo, the following two approaches seem suitable: developing an animal model for eosinophilic BP or performing a specific targeting of eosinophils in BP patients (55).

This article is protected by copyright. All rights reserved. 


\section{Acknowledgments}

This study was funded by grants of the Swiss National Science Foundation (number 310030_166473 to HUS and number 310030_146215 to SY). We thank Natalie Jesch, Christoph Schott, Tamar Grau, Mareike Ebeling, Anja Mettler, and Naïma Zoubiri for providing human neonatal foreskin. We also would like to thank all blood donors.

\section{References}

1. de Graauw E, Beltraminelli H, Simon HU, Simon D. Eosinophilia in Dermatologic Disorders. Immunol Allergy Clin North Am 2015;35:545-60.

2. Simon D, Simon HU. Eosinophilic disorders. J Allergy Clin Immunol 2007;119:12911300.

3. Klion AD, Nutman TB. The role of eosinophils in host defense against helminth parasites. J Allergy Clin Immunol 2004;113:30-37.

4. Yousefi S, Gold JA, Andina N, Lee JJ, Kelly AM, Kozlowski E, et al. Catapult-like release of mitochondrial DNA by eosinophils contributes to antibacterial defense. Nat Med 2008;14:949-953.

5. Morshed M, Yousefi S, Stöckle C, Simon HU, Simon D. Thymic stromal lymphopoietin stimulates the formation of eosinophil extracellular traps. Allergy 2012;67:1127-1137.

6. Roth N, Städler S, Lemann M, Hösli S, Simon HU, Simon D. Distinct eosinophil cytokine expression patterns in skin diseases - the possible existence of functionally different eosinophil subpopulations. Allergy 2011;66:1477-1486.

7. Soragni A, Yousefi S, Stoeckle C, Soriaga AB, Sawaya MR, Kozlowski E, et al. Toxicity of eosinophil MBP is repressed by intracellular crystallization and promoted by extracellular aggregation. Mol Cell 2015;57:1011-1021.

8. Di Zenzo G, Marazza G, Borradori L. Bullous pemphigoid: physiopathology, clinical features and management. Adv Dermatol 2007;23:257-288.

9. Di Zenzo G, Della Torre R, Zambruno G, Borradori L. Bullous pemphigoid: from the clinic to the bench. Clin Dermatol 2012;30:3-16.

10. Büdinger L, Borradori L, Yee C, Eming R, Ferencik S, Grosse-Wilde $H$, et al. Identification and characterization of autoreactive $\mathrm{T}$ cell responses to bullous pemphigoid antigen 2 in patients and healthy controls. J Clin Invest 1998;102:20822089.

This article is protected by copyright. All rights reserved. 
11. Di Zenzo G, Thoma-Uszynski S, Fontao L, Calabresi V, Hofmann SC, Hellmark T, et al. Multicenter prospective study of the humoral autoimmune response in bullous pemphigoid. Clin Immunol 2008;128:415-426.

12. Ameglio F, D'Auria L, Bonifati C, Ferraro C, Mastroianni A, Giacalone B. Cytokine pattern in blister fluid and serum of patients with bullous pemphigoid: relationships with disease intensity. Br J Dermatol 1998;138:611-614.

13. Wakugawa M, Nakamura K, Hino H, Toyama K, Hattori N, Okochi H, et al. Elevated levels of eotaxin and interleukin-5 in blister fluid of bullous pemphigoid: correlation with tissue eosinophilia. Br J Dermatol 2000;143:112-116.

14. Ståhle-Bäckdahl M, Inoue M, Guidice GJ, Parks WC. 92-kD gelatinase is produced by eosinophils at the site of blister formation in bullous pemphigoid and cleaves the extracellular domain of recombinant $180-\mathrm{kD}$ bullous pemphigoid autoantigen. $J$ Clin Invest 1994;93:2022-2030.

15. Borrego L, Maynard B, Peterson EA, George T, Iglesias L, Peters MS, et al. Deposition of eosinophil granule proteins precedes blister formation in bullous pemphigoid. Comparison with neutrophil and mast cell granule proteins. Am J Pathol 1996;148:897-909.

16. Caproni M, Palleschi GM, Falcos D, D’Agata A, Cappelli G, Fabbri P. Serum eosinophil cationic protein (ECP) in bullous pemphigoid. Int J Dermatol 1995;34:177180.

17. Simon D, Hoesli S, Roth N, Staedler S, Yousefi S, Simon HU. Eosinophil extracellular DNA traps in skin diseases. J Allergy Clin Immunol 2011;127:194-199.

18. Feliciani C, Joly $P$, Jonkman MF, Zambruno G, Zillikens D, loannides D, et al. Management of bullous pemphigoid: the European Dermatology Forum consensus in collaboration with the European Academy of Dermatology and Venereology. $\mathrm{Br} \mathrm{J}$ Dermatol 2015;172:867-877.

19. Sitaru C, Schmidt E, Petermann S, Munteanu LS, Bröcker EB, Zillikens D. Autoantibodies to bullous pemphigoid antigen 180 induce dermal-epidermal separation in cryosections of human skin. $J$ Invest Dermatol 2002;118:664-671.

20. Mariotti F, Grosso F, Terracina M, Ruffelli M, Cordiali-Fei P, Sera F, et al. Development of a novel ELISA system for detection of anti-BP180 IgG and characterization of autoantibody profile in bullous pemphigoid patients. $\mathrm{Br} J$ Dermatol 2004;151:1004-1010.

21. Simon HU, Plötz SG, Dummer R, Blaser K. Abnormal clones of T cells producing interleukin-5 in idiopathic eosinophilia. N Engl J Med 1999;341:1112-1120.

This article is protected by copyright. All rights reserved. 
22. Simon HU, Rothenberg ME, Bochner BS, Weller PF, Wardlaw AJ, Wechsler ME, et al. Refining the definition of hypereosinophilic syndrome. J Allergy Clin Immunol 2010;126:45-49

23. Schindelin J, Arganda-Carreras I, Frise E, Kaynig V, Longair M, Pietzsch T, et al. Fiji: an open-source platform for biological-image analysis. Nat Methods 2012;9:676-682.

24. Melo RC, Perez SA, Spencer LA, Dvorak AM, Weller PF. Intragranular vesiculotubular compartments are involved in piecemeal degranulation by activated human eosinophils. Traffic 2005;6:866-879.

25. Gomes A, Fernandes E, Lima JLFC. Fluorescence probes used for detection of reactive oxygen species. J Biochem Biophys Meth 2005;65:45-80.

26. Zhao M, Trimbeger ME, Li N, Diaz LA, Shapiro SD, Liu Z. Role of FcRs in animal model of autoimmune bullous pemphigoid. J Immunol 2006;177:3398-3405.

27. Kaneko M, Horie S, Kato M, Gleich GJ, Kita H. A crucial role for beta 2 integrin in the activation of eosinophils stimulated by IgG. J Immunol 1995;155:2631-2641.

28. Chiriac MT, Roesler J, Sindrilaru A, Scharffetter-Kochanek K, Zillikens D, Sitaru C. NADPH oxidase is required for neutrophil-dependent autoantibody-induced tissue damage. J Pathol 2007;212:56-65.

29. Echeverry N, Bachmann D, Ke F, Strasser A, Simon HU, Kaufmann T. Intracellular localization of the BCL-2 family member BOK and functional implications. Cell Death Differ 2013;20:785-799.

30. Lisauskas T, Matula P, Claas C, Reusing S, Wiemann S, Erfle H, et al. Live-cell assays to identify regulators of ER-to-Golgi trafficking. Traffic 2012;13:416-432.

31. Liu Z, Giudice GJ, Zhou X, Swartz SJ, Troy JL, Fairley JA, et al. A major role for neutrophils in experimental bullous pemphigoid. J Clin Invest 1997;100:1256-1263.

32. Chen R, Fairley JA, Zhao ML, Giudice GJ, Zillikens D, Diaz LA, et al. Macrophages, but not $\mathrm{T}$ and $\mathrm{B}$ lymphocytes, are critical for subepidermal blister formation in experimental bullous pemphigoid: macrophage-mediated neutrophil infiltration depends on mast cell activation. J Immunol 2002;169:3987-3992.

33. Leighty L, Li N, Diaz LA, Liu Z. Experimental models for the autoimmune and inflammatory blistering disease, Bullous pemphigoid. Arch Dermatol Res 2007;299:417-422.

34. Messingham KN, Wang JW, Holahan HM, Srikantha R, Aust SC, Fairley JA. Eosinophil localization to the basement membrane zone is autoantibody- and complement-dependent in a human cryosection model of bullous pemphigoid. Exp Dermatol 2016;25:50-55.

This article is protected by copyright. All rights reserved. 
35. Rico MJ, Benning C, Weingart ES, Streilein RD, Hall RP. Characterization of skin cytokines in bullous pemphigoid and pemphigus vulgaris. $\mathrm{Br} J$ Dermatol 1999;140:1079-1086.

36. Stanley JR. A specific antigen-antibody interaction triggers the cellular pathophysiology of bullous pemphigoid. Br J Dermatol 1985;113 Suppl 28:67-73.

37. Liu Z, Diaz LA, Troy JL, Taylor AF, Emery DJ, Fairley JA, et al. A passive transfer model of the organ-specific autoimmune disease, bullous pemphigoid, using antibodies generated against the hemidesmosomal antigen, BP180. J Clin Invest 1993;92:2480-2488.

38. Ishiko A, Shimizu $H$, Kikuchi A, Ebihara $T$, Hashimoto $T$, Nishikawa T. Human autoantibodies against the 230-kD bullous pemphigoid antigen (BPAG1) bind only to the intracellular domain of the hemidesmosome, whereas those against the $180-k D$ bullous pemphigoid antigen (BPAG2) bind along the plasma membrane of the hemidesmosome in normal human and swine skin. J Clin Invest 1993;91:1608-1615.

39. Giudice GJ, Emery DJ, Zelickson BD, Anhalt GJ, Liu Z, Diaz LA. Bullous pemphigoid and herpes gestationis autoantibodies recognize a common non-collagenous site on the BP180 ectodomain. J Immunol 1993;151:5742-5750.

40. Perriard J, Jaunin F, Favre B, Büdinger L, Hertl $M$, Saurat JH, et al. IgG autoantibodies from bullous pemphigoid (BP) patients bind antigenic sites on both the extracellular and the intracellular domains of the BP antigen 180. J Invest Dermatol 1999;112:141-147.

41. Valerius T, Repp R, Kalden JR, Platzer E. Effects of IFN on human eosinophils in comparison with other cytokines. A novel class of eosinophil activators with delayed onset of action. J Immunol 1990;145:2950-2958.

42. Hartnell A, Kay AB, Wardlaw AJ. IFN-gamma induces expression of Fc gamma RIII (CD16) on human eosinophils. J Immunol 1992;148:1471-1478.

43. Ghohestani RF, Cozzani E, Delaporte E, Nicolas JF, Parodi A, Claudy A. IgE antibodies in sera from patients with bullous pemphigoid are autoantibodies preferentially directed against the 230-kDa epidermal antigen (BP230). J Clin Immunol 1998;18:202-209.

44. Döpp R, Schmidt E, Chimanovitch I, Leverkus M, Bröcker EB, Zillikens D. IgG4 and $\operatorname{lgE}$ are the major immunoglobulins targeting the NC16A domain of BP180 in Bullous pemphigoid: serum levels of these immunoglobulins reflect disease activity. $J \mathrm{Am}$ Acad Dermatol 2000;42:577-583.

45. Fairley JA, Baum CL, Brandt DS, Messingham KAN. Pathogenicity of $\lg E$ in autoimmunity: successful treatment of bullous pemphigoid with omalizumab. $J$ Allergy Clin Immunol 2009;123:704-705.

This article is protected by copyright. All rights reserved. 
46. Dimson OG, Giudice GJ, Fu CL, Van den Bergh F, Warren SJ, Janson MM, et al. Identification of a potential effector function for $\lg E$ autoantibodies in the organspecific autoimmune disease bullous pemphigoid. J Invest Dermatol 2003;120:784788.

47. Kita H, Kaneko M, Bartemes KR, Weiler DA, Schimming AW, Reed CE, Gleich GJ. Does $\lg \mathrm{E}$ bind to and activate eosinophils from patients with allergy? $\mathrm{J}$ Immunol 1999;162:6901-6911.

48. Seminario MC, Saini SS, MacGlashan DW Jr, Bochner BS. Intracellular expression and release of Fc epsilon RI alpha by human eosinophils. J Immunol 1999;162:68936900

49. Karashima T, Hachisuka H, Okubo K, Sasai Y. Epidermal keratinocytes of bullous pemphigoid express intercellular adhesion molecule-1 (ICAM-1). J Dermatol 1992;19:82-86.

50. Hartnell A, Moqbel R, Walsh GM, Bradley B, Kay AB. Fc gamma and CD11/CD18 receptor expression on normal density and low density human eosinophils. Immunology 1990;69:264-270.

51. Scheman AJ, Hordinsky MD, Groth DW, Vercellotti GM, Leiferman KM. Evidence for eosinophil degranulation in the pathogenesis of herpes gestationis. Arch Dermatol 1989;125:1079-1083.

52. Tsuda S, Miyasato M, Iryo K, Nakama T, Kato K, Sasai Y. Eosinophil phenotypes in bullous pemphigoid. J Dermatol 1992;19:270-279.

53. Kobayashi T, Robinson JM, Seguchi H. Identification of intracellular sites of superoxide production in stimulated neutrophils. J Cell Sci 1998;111:81-91.

54. Someya A, Nishijima K, Nunoi H, Irie S, Nagaoka I. Study on the superoxideproducing enzyme of eosinophils and neutrophils--comparison of the NADPH oxidase components. Arch Biochem Biophys 1997;345:207-213.

55. Radonjic-Hoesli S, Valent P, Klion AD, Wechsler ME, Simon HU. Novel targeted therapies for eosinophil-associated diseases and allergy. Annu Rev Pharmacol Toxicol 2015;55:633-656

\section{Figure legends}

Figure 1 Activated eosinophils cause tissue damage. (A) Histology. Quantification of DES induced by leukocytes, neutrophils, and eosinophils in the presence and absence of BP autoantibodies. Values are means of the \% separation \pm SEM. ${ }^{* * *}, p<0.001 ;{ }^{* * *}, p<0.0001$; $n=3$. (B-D) Representative images (H\&E) show the extent of DES (arrows) induced by eosinophils (panel B), leukocytes (panel C), and neutrophils (panel D) in the presence of 
BPS. (E) Histology. Quantification of tissue damage and DES by activated eosinophils. Eosinophils were stimulated as indicated in the absence of BP autoantibodies. Values are means \pm SEM. $n=3$. Each single experiment was performed with 6 cryosections. $(F-H)$ Representative images (H\&E) show the extent of tissue damage and DES (arrows) induced by eosinophils activated with IL-5 (panel F) or PMA (panel G) in the absence of BP autoantibodies. Asterisks point to extracellular eosinophil granules. PMA alone did not harm the skin (panel H). Magnification x20, except in panel B x40.

Figure 2 Synergistic effect of IL-5 and BP autoantibodies on DES. (A) Histology. Quantification of DES induced by eosinophils in the presence and absence of IL-5 and BP autoantibodies. Values are means of \% separation \pm SEM. ${ }^{* *}, p<0.01 ;{ }^{* \star * *}, p<0.0001 ; n=3$. (B-D) Representative images (H\&E) show the extent of DES (arrows) induced by IL-5activated eosinophils in the presence of BP autoantibodies (panel B) as well as a tight lining of eosinophils under these conditions along the dermal-epidermal junction after $3 \mathrm{~h}$ (panel C). Little DES is observed with normal serum only (panel D). Magnification x20.

Figure 3 DES induced by eosinophils in the presence of IL-5 and BP autoantibodies requires FcpR activation and adhesion. (A) Histology. Quantification of DES induced by activated eosinophils in the presence and absence of $F\left(a b^{\prime}\right)_{2}$ antibody fragments against CD16, CD32 and CD64. Values are means of the \% separation \pm SEM. $n=3$. $(B, C)$ Representative images (H\&E) show the extent of DES (arrows) induced by activated eosinophils in the presence of control $F\left(a b^{\prime}\right)_{2}$ antibody fragments (panel $B$ ) and blocking $\mathrm{F}\left(\mathrm{ab}^{\prime}\right)_{2}$ antibody fragments against CD16, CD32 and CD64 (panel C). Magnification x20. (D) Histology. Quantification of DES induced by activated eosinophils in the presence and absence of $F\left(a b{ }^{\prime}\right)_{2}$ antibody fragments against CD18. Values are means of the \% separation \pm SEM. $n=3$. ( $E, F)$ Representative images (H\&E) show the extent of DES (arrows) induced by activated eosinophils in the presence of control $F\left(a b^{\prime}\right)_{2}$ antibody fragments (panel $E$ ) and blocking $\left.\mathrm{F}(\mathrm{ab})_{2}\right)_{2}$ antibody fragments against CD18 (panel $\mathrm{F}$ ). Magnification x20.

Figure 4 ROS production, degranulation and EET formation are involved in eosinophilmediated DES in the presence of IL-5 and BP autoantibodies. (A) Histology. Quantification of DES induced by activated eosinophils in the presence and absence of different concentrations of DPI. Values are means of the \% separation \pm SEM. ${ }^{*}, p<0.05 ;{ }^{* *}, p<0.01$; 
$n=3$. (B) Histology. Quantification of DES induced by activated eosinophils in the presence and absence of brefeldin $A$. Values are means of the \% separation \pm SEM. $n=3$. (C) Histology. Quantification of DES induced by activated eosinophils in the presence and absence of DNase. Values are means of the \% separation \pm SEM. $n=3$. (D-G) Representative images (H\&E) show the extent of DES (arrows) induced by activated eosinophils in the absence of drugs (panel D) and in the presence of DPI (panel E), brefeldin A (panel F), and DNase (panel G). Magnification x20. (H) ROS production assay. ROS production by eosinophils was analyzed over a time period of $2 \mathrm{~h}$. Eosinophils were activated as indicated. Conditions in the presence of BP antibodies are labelled in red. Data are representative of three independent experiments.

This article is protected by copyright. All rights reserved. 

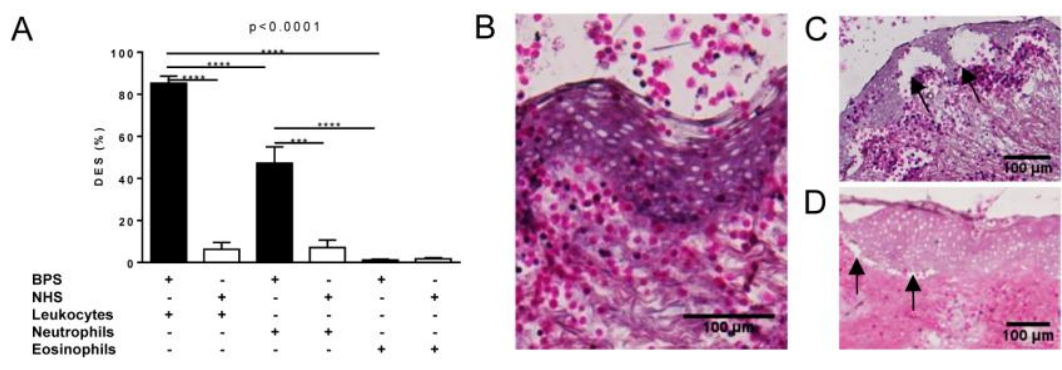

E

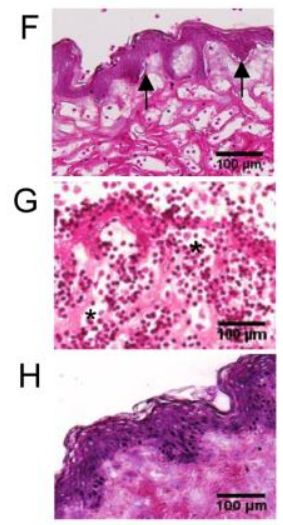

Figure 1

This article is protected by copyright. All rights reserved. 
A

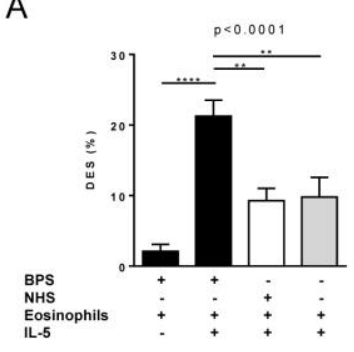

B
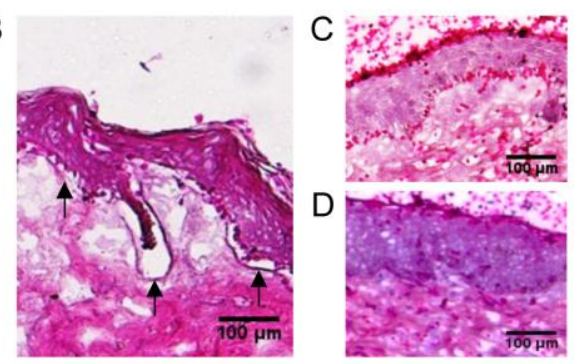

Figure 2

This article is protected by copyright. All rights reserved. 

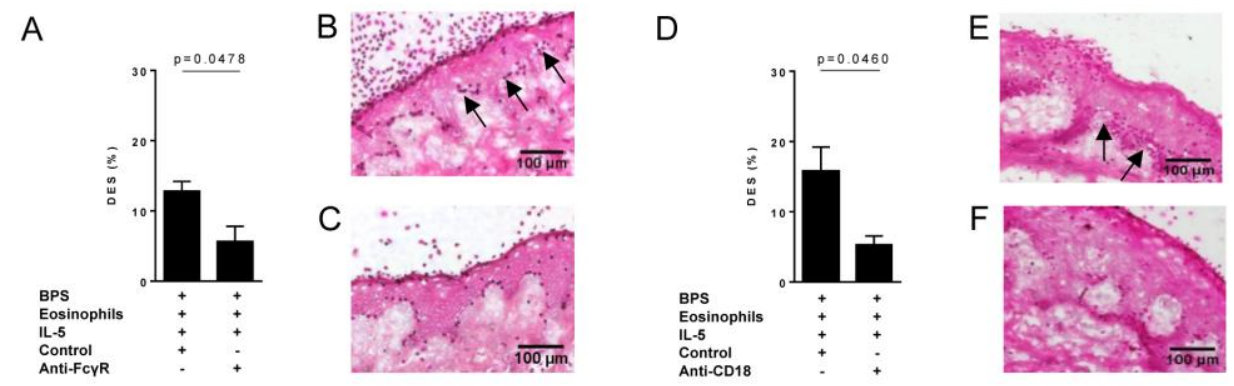

Figure 3

This article is protected by copyright. All rights reserved. 


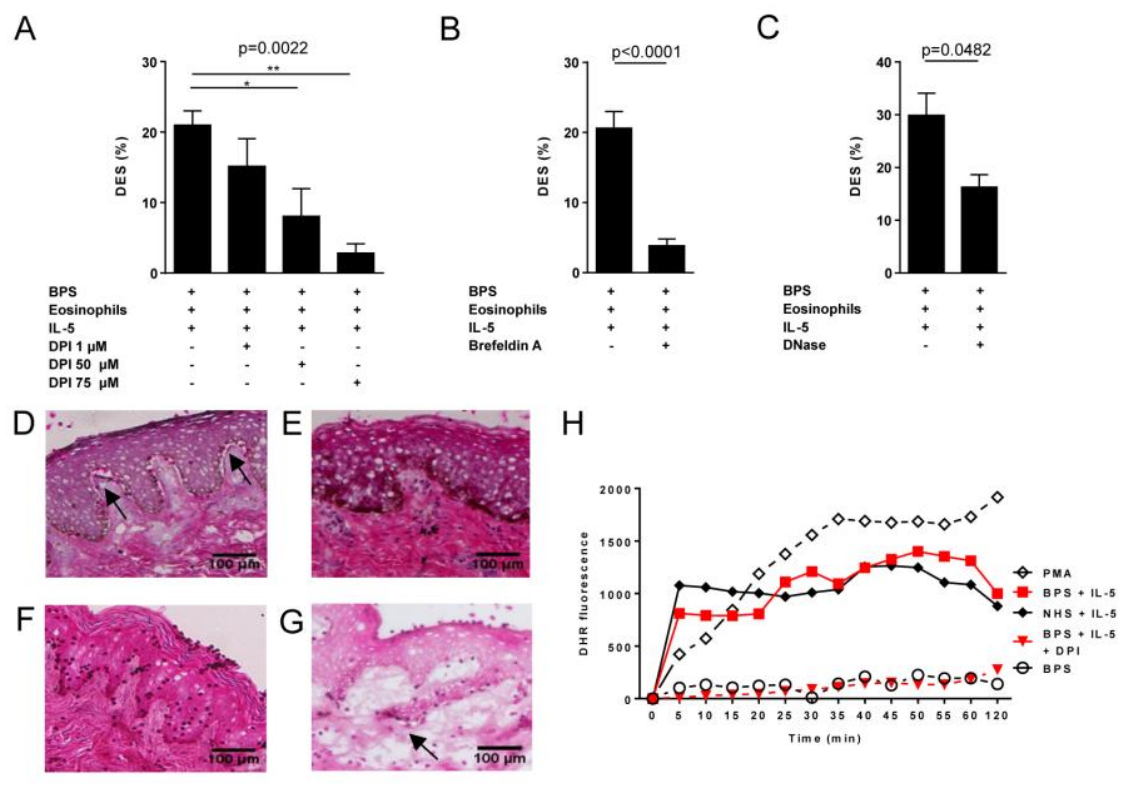

Figure 4

This article is protected by copyright. All rights reserved. 